\title{
SEXUALIDAD Y CONOCIMIENTO: LA CONQUISTA DE UNO MISMO EN LA OBRA DE ERNESTO SABATO
}

\section{Luis Montiel}

Unos cuantos investigadores, procedentes de diversas áreas de las llamadas Ciencias Humanas, nos encontramos reunidcs con la pretensión de deslizar nuestras personales reflexiones en la ya raudalosa corriente del discurso sobre la sexualidad humana. Al enf rentarme con mi tarea no puedo dejar de recordar el riesgo inherente a este empeño, del que no hace mucho nos previno Michel Foucault:

Después de decenas de años, nosotros no hablamos del s axo sin posar un poco: consciencia de desafiar el orden establecido, tono de voz que muestra que uno se sabe subversivo, ardor en conjurar el presente y en llamar a un futuro cuya hora uno piensa que contribuye a apresurar. Algo de la revuelta, de la libertad prometida y de la próxima época de otra ley se filtran fácilmente en ese discurso sobre la opresión del sexo. En el mismo se encuentran reactivadas viejas funciones de la profecía (1).

Esto es cierto cuando se parte de la premisa - tan mendaz e interesada, según el filósofo francés- de que el de la sexualidad y su ejercicio habría sido, durante siglos, un ámbito proscrito, cerrado al lenguaje y a la reflexión, creencia ésta de la que aún no nos habríamos liberado del todo, pues: 
... tal vez hay (una) razón que torna tan gratificante para nosotros el formular en términos de represión las relaciones del sexo y el poder: lo que podría llamarse el beneficio del locutor. Si el sexo está reprimido, es decir, destinado a la prohibición, a la inexistencia y al mutismo, el sólo hecho de hablar de él, y de hablar de su represión, posee como un aire de transgresión deliberada (2).

No obstante, el hecho de que realmente haya existido y exista aún - me guardaré de pronosticar el futuro- una cierta atmósfera de inquietud en torno al complejo mundo de la sexualidad humana, legitima la contínua apertura de discursos sobre el tema. Obligación de quien reflexiona es explicar, al menos parcialmente, en qué consiste la acuciante problematicidad de este dominio antropológico, problematicidad que, en un momento histórico que habría que considerar pasado, trató de formularse tan sólo en términos de represión ejercida por un poder exterior al sujeto. En mi opinión es preciso seguir hablando de la sexualidad, reflexionar sobre su misterio, preguntarse sobre esa facultad que, al menos en la especie humana, desborda en todas direcciones el marco biológico que es su soporte. La prolija y lamentablemente inconclusa investigación de Foucault nos libera en parte de la hipótesis represiva entendida al modo tradicional, y nos permite buscar las razones de lo temible, de lo informulable de la sexualidad humana en otra parte.

El título de mi colaboración vincula - y precisamente mediante una conjunción copulativa - sexualidad y conocimiento. No creo que a nadie le resulte extraña esta asociación, vigente en el pensamiento occidental -y, más exactamente, cristiano- al menos desde la Edad Media (3). Y si hago hincapié en el carácter copulativo de la conjunción, ello no se debe - o al menos, no en primer término- a una intención lúdica, sino a la pretensión de explicitar que no hablaré del «conocimiento de la sexualidad", del cúmulo de discursos que en torno a la sexualidad ha tramado nuestra cultura -eso que Foucault en la obra citada llama scientia sexualis - sino de la turbadora asociación entre sexualidad y saber que, en una capa más profunda, también se ha mantenido a lo largo de toda la historia de la civilización occidental.

Ars, scientia, gnosis

En su Historia de la sexualidad Foucault señala como rasgo característico y distintivo del pensamiento occidental el hecho de que, a di- 
ferencia del oriental, no muestra especial interés por establecer una ars erotica como la que desarrollarán, cada una a su modo, las culturas japonesa, china, india e islámica. La antigua Roma, tal vez por su cosmopolitismo, habría sido la única excepción. Europa - sobre todo desde la Edad Media, pero sin olvidar la etapa hegemónica del pensamiento griego - habría desarrollado a cambio una scientia sexualis. Aparentemente, ni tal ciencia ni tal arte son excesivamente locuaces, ambas se mueven en el secreto; aparentemente:

En el arte erótico la verdad es extraída del placer mismo, tomado como práctica y recogido como experiencia; ese saber debe ser revertido sobre la práctica sexual, para trabajarla desde el interior y amplificar sus efectos. Así se constituye un saber que debe permanecer secreto, no por una sospecha de infamia (...) sino porque (...) perdería su eficacia y su virtud si fuera divulgado (4).

En todo caso - como el autor pone inmediatamente de relieve- existe un desvelamiento de lo oculto a través de la iniciación. Por su parte, la scientia sexualis esconde desde la Edad Media, tras el tópico «secreto de confesión", todo un haz de

... procedimientos para decir la verdad del sexo, que en lo esencial corresponden a una forma de saber rigurosamente opuesta al arte de las iniciaciones y al secreto magistral (...) La confesión se convirtió, en Occidente, en una de las técnicas más altamente valoradas para producir lo verdadero (5).

En un lugar intermedio dentro de este espacio de silencio quebrado, cuando no ficticio, se sitúa un pensamiento clandestino cuya pretensión de conocimiento es tan fundamental como para darle nombre: me refiero al gnosticismo, que comparte con el lenguaje del ars erotica el carácter iniciático, y con la scientia sexualis - no olvidemos que nació del cristianismo- el anhelo del conocimiento de sí y, a la postre, de la divinidad. Se ha señalado hasta qué punto la obra de Ernesto Sabato es deudora de la tradición gnóstica (6), por lo que me ha parecido oportuno instalar, entre las dos aproximaciones a la sexualidad planteadas por Foucault, esta tercera que, inopinadamente, rebrota en la segunda mital del siglo veinte en una obra leída y celebrada por millones de personas. En la narrativa de Sabato no hay en absoluto ars erotica, pero sí un atormentado arte de la confesión y una pesquisa en el interior de sí mismo y de los otros a través de la sexualiddad: una cier- 
ta scientia sexualis que ya no produce, pero enuncia un conocimiento - gnosis - adquirido mediante una dolorosa e incluso temible introspección. En otros trabajos (7) he tratado de mostrar algunos de los elementos de este autoanálisis - tómese el término en su sentido más alto- así como ponerlo en relación con distintos dominios de las humanidades - filosofía, historia de las religiones, onirocrítica pre y postsicoanalítica...- intentando situar al escritor y a su tema en el seno de una corriente prácticamente ininterrumpida de discursos sobre el conocimiento de uno mismo que comparten un punto de arranque: la conciencia de una escisión, de un dualismo, de una polaridad cuando menos, que está en la base de la existencia individual. En el presente trabajo aplicaré una pauta interpretativa que no había seguido hasta el momento, pero que comparte con las anteriores lo esencial: la idea de que la indagación realizada por Sabato en su novelística no ha dejado de producirse en la historia de la humanidad al menos desde el surgimiento de un pensamiento religioso elaborado, y que, bajo distintas manifestaciones y en distinto grado, se da o puede darse en todo ser humano: de ahí el interés que las novelas del escritor argentino tienen para lectores tan diversos.

\section{Dualismo y escisión}

En algunos de los trabajos a que antes me refería me he ocupado del dualismo cuerpo-alma en la obra de Sabato (8). En esta ocasión me interesa mucho menos establecer el significado de los conceptos de alma y cuerpo en el pensamiento sabatiano, que señalar hasta qué punto este dualismo introduce una peligrosísima escisión en la existencia de quien lo vive, de quien se representa en su conciencia este carácter compuesto de lo que llama su Yo. Para ello seguiré, fundamentalmente, la guía suministrada por los estudios de C. G. Jung sobre la alquimia. ¿Por qué esta elección? En primer lugar, porque el dualismo es elemento fundamental del pensamiento gnóstico - y en particular del maniqueismo, del que tantas pruebas se encuentran en la obra de Sabato (9)-, y la asociación entre gnosis y alquimia ha sido ya definitivamente establecida, entre otros por el propio Jung (10). Pero, además, la tesis central de los escritos del psicoanalista suizo sobre el arte hermética es perfectamente aplicable a la obra de ficción de Sabato: según Jung, la obra hermética no era otra cosa que un símbolo del proceso de individuación (11). Otro tanto puede decirse de las historias narradas por el 
escritor argentino. Sostiene Jung que «sin la experiencia de lo contradictorio no existe experiencia alguna de la totalidad» (12) y, como Sabato ha declarado en multitud de ocasiones, lo que ha buscado a través de su creación literaria ha sido precisamente esto, una experiencia de la totalidad superadora de la escisión, y hay que decir que el grado de claridad alcanzado por él es muy superior al conseguido por los espagíricos medievales y modernos. Ellos, nos dice Jung, "proyectaban » su propio inconsciente sobre el proceso protoquímico que realizaban (13), y lo que se desplegaba ante sus ojos era - en palabras de Bachelard- «un combate intestino de las sustancias (...) un verdadero maniqueísmo de la materia» (14); mientras que el novelista sabe perfectamente de qué está hablando cuando nos muestra esos mismos «combates intestinos»: nos habla de sí mismo y del hombre en general. Fernando Vidal Olmos es el doble oscuro de Sabato en Sobre héroes y tumbas, su particular «Mr. Hyde»; lo que Jung llama «la sombra»: El proceso de individuación que el psicoanalista estudia a través de la simbología de la alquimia consiste, en síntesis, en la toma de conciencia de esta «sombra» (el inconsciente personal); y este proceso arrastra siempre a la superficie imágenes del inconsciente colectivo, no fácilmente racionalizables, que despiertan en el sujeto el miedo a volverse lorn (15). Fernando Vidal reconoce, en su "Informe sobre ciegos", haber experimentado este temor en su infancia, cuando un sueño repetido le atormentaba:

Veía un chico (y ese chico, hecho curioso, era yo mismo, y me veía y observaba como si fuera otro) que jugaba en silencio a un juego que yo no alcanzaba a entender (...) De pronto, mirándome gravemente, me decía: observo la sombra de esta pared en el sueño, y si esa sombra llega a moverse no sé lo que puede pasar. Había en sus palabras una sobria pero horrenda expectativa. Y entonces yo también empezaba a controlar la sombra con pavor. No se trataba, inútil decirlo, del trivial desplazamiento que la sombra pudiese tener por el simple movimiento del sol: era OTRA COSA (16).

Más tarde, ya en edad adulta, Fernando comprenderá que el sueño era solamente la oscura precognición de una verdad terrible:

Cuando yo tenía menos de veinte años (...) tuve de pronto la revelación de que la realidad podía empezar a deformarse si no concentraba toda mi voluntad para mantenerla estable (...) Como si me viese obligado a anclar la realidad, pero como si el barco estuviese compuesto 
de muchos pedazos separables y fuese necesario primero atarlos a todos y luego largar una formidable ancla para que el todo no fuese la deriva (...) La gente no comprendía lo que me pasaba, me veía concentrarme, con mi mirada fija y ajena, y creía que me estaba volviendo loco, sin comprender que era al revés, puesto que merced a aquel esfuerzo lograba mantener la realidad en su sitio y en su forma (17).

Vidal $-\mathrm{y}$, con él, su creador- descubre la ingenuidad latente en el concepto de «individuo", puesto que él se sabe radicalmente dividido, y no en dos, sino tal vez en innumerables fragmentos. Ha vivenciado el incomparable poder disolvente de la sombra cuando se muestra a la conciencia, y morirá por ello. Si Sabato ha de sobrevivir sin volverse loco, será al precio de una boda mística, de una hierogamia entre lo oscuro y lo distinto; y esta unión será tan íntima que sólo pude simbolizarse adecuadamente mediante la metáfora del incesto, de la unión con lo más próximo pero, a la vez, diferente.

\section{El andrógino y el murciélago}

La conciencia de esa radical escisión, para la que la naturaleza parece haber tramado la imagen perfecta de la diferencia de los sexos, ha movido a los hombres a lo largo del tiempo a representarse la soñada unión definitiva bajo la figura del andrógino. A este respecto es muy ilustrativo el abordaje de esta metáfora realizado por Eliade en Mefistófeles y el Andrógino o el ministerio de la totalidad (18). Simulacro de esta unión ideal es el acto sexual, que no se convierte en auténtica vía hacia el conocimiento si no va acompañado de una identificación con el otro - en el acto en sí, tomado en su realidad material, no simbólicay, sobre todo, con lo Otro - en lo que atañe a la duplicidad o multiplicidad solitaria de cada cual-. En su dimensión puramente real el acto sexual tiene, en la obra de Sabato, el valor nada despreciable, pero a todas luces escaso, revelador de la profundidad de un problema esencial cuya solución no constituye. Juan Pablo Castel, el protagonista de El túnel, vivirá trágicamente su incomunicación con la amada hasta llegar al asesinato. Su conclusión es explícita:

Y era como si los dos hubiéramos estado viviendo en pasadizos o túneles paralelos, sin saber que íbamos uno al lado del otro, como almas semejantes en tiempos semejantes, para encontrarnos al fin de esos pasadizos, delante de una escena pintada por mí, como clave des- 
tinada a ella sola, como un secreto anuncio de que ya estaba yo allí y que los pasadizos se habían unido y que la hora del encuentro había llegado.

- (...) Pero, ¿realmente los pasadizos se habían unido y nuestras almas se habían comunicado? ¡Qué estúpida ilusión mía había sido todo esto! No, los pasadizos seguían paralelos como antes, aunque ahora el muro que los separaba fuera como un muro de vidrio (...) No, ni siquiera ese muro era siempre así: a veces volvía a ser de piedra negra y entonces yo no sabía qué pasaba del otro lado (...) y hasta pensaba (...) que en todo caso había un solo túnel, oscuro y solitario: el mío, el túnel en el que había transcurrido mi infancia, mi juventud, toda mi vida (19).

Por su parte, Martín, en Sobre héroes y tumbas, experimenta una radical insatisfacción que hace irrelevante, que invalida incluso la mera satisfacción física cuando se une con Alejandra:

Arrastrado por el cuerpo, en medio del tumulto y de la consternación de la carne, el alma de Martín trataba de hacerse oir por el otro que estaba del otro lado del abismo (...). Y Martín trataba de llegar, de sentir, de entender a Alejandra tocando su cara, acariciando su pelo, besando sus orejas, su cuello, sus pechos, su vientre, como un perro que busca un tesoro escondido (...) Y así como el perro, cuando siente de pronto más próximo el misterio buscado, empieza a cavar con febril y casi enloquecido fervor (...) así acometía (Martín) el cuerpo de Alejandra, trataba de penetrar en ella hasta el fondo del doloroso enigma (...) Y mientras Martín cavaba, Alejandra quizá luchaba desde su propia isla, gritando palabras cifradas que para él, Martín, eran ininteligibles y para ella, Alejandra, probablemente inútiles, y para ambos desesperantes (20).

Corresponde, como queda dicho, a Fernando Vidal realizar la única cópula que conduce a la sabiduría: una cópula que es a la vez efracción y pesquisa, que conduce a lo más oscuro para introducir en su fondo la luz del conocimiento, y que se produce tanto en una dimensión real como en la simbólica. Su camino recuerda en todo al seguido por los alquimistas en su esfuerzo por encontrar lo que no en vano se llama rebis.

Soy un investigador del Mal ¿y cómo podría investigarse el Mal sin hundirse hasta el cuello en la basura? (...) Así fui advirtiendo detrás de las apariencias el mundo abominable. Y así fui preparando 
mis sentidos, exacerbándolos por la pasión y la ansiedad, por la espera y el temor, para ver finalmente las grandes fuerzas de las tinieblas como los místicos alcanzan a ver al dios de la luz y de la bondad. Y yo, místico de la Basura y del Infierno, puedo y debo decir: $•$ ¿CREED EN MI! (21).

¡Cómo evoca este texto la impetración de aquel alquimista que pedía a Dios: Horridas nostrae mentis purga tenebras! (22), si bien existe una diferencia fundamental entre éste y Fernando: el Doppelgänger de Sabato desea, precisamente, "ver las grandes fuerzas de las tinieblas». Solamente un personaje como este podía acometer una indagación en lo oscuro, en el mundo sin luz de los ciegos, identificado por Sabato en Abaddón con el mundo del sueño: «Al dormir cerramos los ojos y, por tanto, NOS CONVERTIMOS EN CIEGOS» (23). Y era necesario que alguien se entregase a esta aventura. En la primera parte de su viaje por el submundo -en el recorrido por las cloacas, esto es: en aquella parte en la que no puede asegurarse que lo que se describe es una experiencia onírica- Fernando se da cuenta de que su pesquisa dista de ser inútil. A través de la metáfora del fétido laberinto nos hace ver cómo

... todo marchaba hacia la Nada del océano mediante conductos subterráneos y secretos, como si Aquellos de Arriba se quisiesen olvidar, como si intentaran hacerse los desentendidos sobre esta parte de su verdad. Y como si héroes al revés, como yo, estuvieran destinados al trabajo infernal y maldito de dar cuenta de esa realidad (...) Sí, de pronto me sentí una especie de héroe, de héroe al revés, héroe negro y repugnante, pero héroe. Una especie de Sigfrido de las tinieblas, avanzando en la oscuridad y la fetidez con mi negro pabellón restallante, agitado por los huracanes infernales (24).

Acabamos de tropezar con algunos de los temas que Jung ha señalado en su interpretación de la obra alquimista como proceso de individuación: en primer lugar, la metáfora de la ceguera, ubicua en la obra sabatiana. Vidal se introduce en el mundo de los ciegos para desvelarlo, como si respondiera a la consigna lanzada por Jung en su estudio del Rosarium Philosophorum:

No puede constituir por cierto un ideal valedero el que los hombres vivan continuamente en un estado infantil, ciegos con respecto a sí mismos (25). 
También Martín, en Sobre héroes y tumbas, asocia la ceguera a la puerilidad:

Ciegos, ciegos: la infancia, la noche, las tinieblas (26).

Pero no es ésta la única coincidencia que se da entre el «Informe sobre ciegos" y los estudios junguianos: en el citado fragmento aparecen dos metáforas - la Nada del Océano y la idea de nigredo- características de las primeras etapas del proceso alquímico. Y el final del viaje de Fernando por el mundo subterráneo lo constituye una múltiple y monstruosa cópula con una divinidad que no es otra que Alejandra. Para consumar esta unión Fernando, sin perder su carácter humano -o más exactamente, sin perder la conciencia- adopta sucesivamente la forma de diversos animales, reales unos, procedentes los otros del bestiario onírico: centauro, unicornio, serpiente, pulpo, vampiro, sátiro, tarántula, salamandra... (27). Más tarde, ya en Abaddón el exterminador, será el propio Sabato quien consume una unión sexual con «Soledad» -nombre a todas luces no elegido al azar-, desgarrando su «ojo sexual» (28). La correspondencia existente entre lo descrito en ambas novelas y lo que Jung ha visto en el proceder de los autores alquimistas es, como trataré de mostrar, extraordinaria.

La serie de láminas del Rosarium estudiadas por Jung muestran, mediante metáforas en primer término sexuales, los pasos de esa aventura que puede conducir tanto a la locura como al conocimiento del sí-mismo. La primera de estas láminas presenta al rey y la reina, caracterizados cada uno de ellos por un símbolo astral: el sol y la luna, Apolo y Diana, hermanos - no lo olvidemos-en la mitología de la que se toma el símbolo. No puedo extenderme en detalle sobre la interpretación de todo lo que se manifiesta en la lámina, tal como hace Jung; baste, pues, con señalar que, ya en esta primera ilustración, se muestra de forma inequívoca la unión, pendiente de consumación, de los hermanos estelares. Incestuosa unión, como la de Fernando y Alejandra, que explica así el psicoanalista suizo:

El incesto simboliza la unión con la esencia propia, la individuación o el devenir uno mismo (29).

A través del incesto Fernando accede a los subterráneos de la podredumbre que conducen a la Nada del Océano. En la lámina quinta del Rosarium contemplamos la coniunctio sive coitus del rey y la reina 
sumergidos bajo el mar, coniunctio que lleva, en la lámina séptima, a , la conceptio seu putrefactio. Curiosa asociación, ésta de putrefacción y concepción: algo debe morir - Fernando acribillado por Alejandra, ella misma quemada en el interior del mirador-para que se produzca la concepción de algo nuevo. Las «bodas químicas» son, a la postre, unas bodas de fuego de las que tal vez surgirá una criatura nueva. El alma "vieja», que el Yo aún no se había apropiado, abandona el cuerpo ya andrógino - figura octava - para regresar al fin en un nuevo nacimiento -ortus, figura décima - al cuerpo dúplice que la recibe, alzándose al fịn como andrógino triunfante, como símbolo de la unión de los complementarios antaño opuestos.

¿Es éste un final feliz? En absoluto: todo lo más. se trata de un final justo. El ascenso a la conciencia de lo inconsciente, de lo pulsional, representado - y no por azar - mediante la metáfora de la coniunctio, la putrefactio y el ortus: unión sexual, muerte y renacimiento bajo una forma monstruosa - tómese el término en su sentido prístino- no representa el final de los conflictos, de las tensiones, sino, todo lo más, el problemático señorío sobre ellas. En la base de la figura décima aparecen dos pájaros; uno de ellos puede volar, no así el otro. El andrógino con que concluye la serie puede volar: pero las suyas son alas de murciélago: como lo son las que crecen al propio Sabato después de su unión con Soledad:

Sin que atinara a nada (¿para qué gritar? ¿Para que la gente al llegar lo matara a palos, asqueada?). Sabato observó cómo sus pies se iban transformando en patas de murciélago (...) Su asco se hizo más intenso cuando se le formaron las alas (...) pero cuando el proceso alcanzó la cabeza (...) su horror alcanzó la máxima e indescriptiblé intensidad (...) El había pertenecido siempre a la clase de gente que siente invencible asco ante una rata. Es imaginable, pues, lo que podía sentir ante una rata de un metro veinte, con inmensas alas cartilaginosas, con la repulsiva piel arrugada de esos monstruos. Y él dentro! (30).

Aunque más auténtico, el estado alcanzado no es más cómodo, no se resuelve en un tímido pacto entre lo consciente conocido y lo inconsciente reciẹn descubiẹto:

La nueva personalidad no es, de ningún modo, un tercero entre lo consciente y lo inconsciente, sino que es estos dos juntos. Es trascendente a la conciencia, y, por tanto, ya no debe calificarse de yo sino de si-mismo (31). 
El sí-mismo es el andrógino con alas de murciélago, problemático ser constituido por la unión de una pluralidad aceptada, masculina y femenina, consciente e inconsciente, luminosa y oscura: la metáfora de la unión en la tensión como suma de la sabiduría sobre lo humano; el destino de una existencia entendida como búsqueda, tal como Sabato la concibe en el prólogo de su primer libro de ensayos:

Uno se embarca hacia tierras lejanas, o busca el conocimiento de hombres, o indaga la naturaleza, o busca a Dios; después se advierte que el fantasma que se perseguía era Unomismo (32).

Sí: «el auténtico camino que lleva a la totalidad es una longissima via» (33); y la totalidad no es, como queda dicho, un mero happy end. Aunque tal vez sí equivale a una vida más plena, pues si aceptamos que la muerte es quietud y la vida es acción,

... el mal exige ser tan sopesado como el bien, pues el bien y el mal no son, a fin de cuentas, sino prolongaciones y abstracciones ideales de la acción (34).

\section{Conclusión}

Esta, metafórica, no es la única forma de abordar la sexualidad. Pero cabe pensar que quien cumple en sí las bodas místicas estará al menos un paso más lejos que Martín del abismo de incomunicación que contemplábamos en el citado texto de Sobre héroes y tumbas. Algo parecido pensaba Nietzsche al escribir en su Zarathustra:

Eres joven, y quieres tener una mujer y un hijo. Y yo te pregunto: ¿¿Eres hombre que pueda permitirse desear un hijo?

$¿$ Eres el victorioso, el dominador de tí mismo (...) ¿O ese deseo no es más que la voz del animal y de la necesidad? ¿O es que tienes miedo de estar solo?

(...) Algún día tendréis que amar más allá de vosotros mismos. ¡Aprended, pues, a amar!

¡Y para ello apurad el cáliz del amor hasta las heces!

Hasta el cáliz del mejor amor encontraréis amargura. Pero esta amargura despierta la sed del superhombre y del creador» (35).

Para que pueda darse la unión de dos es preciso, primero, instaurar la unidad problemática simbolizada por ese andrógino que es el Uno- 
mismo. Por eso el ingente ciclo indagatorio de Ernesto Sabato concluye con un poema que es una pregunta: pregunta que ha encontrado respuesta una vez - pero que ha de contestarse veces innumerables- en el despliegue de la escritura sabatiana:

\author{
$¿$ Es el alma un extraño en la tierra? \\ ¿Adónde dirige sus pasos? \\ Es la voz lunar de la hermana a través de la niebla sagrada la que oye \\ el peregrino \\ el sombrío \\ en su barca nocturna \\ en los estanques lunares \\ entre podridos ramajes, entre muros leprosos (36).
}

\title{
NOTAS
}

(1) Foucault, M. (1984): Historia de la sexualidad, I (La voluntad de saber). México, Siglo XXI, p. 13

(2) Ibid.

(3) Foucault, M. (1986): Historia de la sexualidad, II (El uso de los placeres). México, Siglo XXI, pp. 89-91. En el mismo sentido se pronuncia TRİAS, E. (1988) en su Tratado de la pasión. Madrid, Mondadori.

(4) Foucault, M. (1984): p. 72.

(5) Ibid., pp. 73-74.

(6) Esta vía de investigación, iniciada por S. BACARISSE [(1980). «Abaddón el exterminador. Sabato's gnostic Escathology ». Contemporary Latin American Fiction, Edimburgo, pp. 88-109], ha sido luego desarrollada en otros estudios: Teodorescu, P. (1983): «El camino hacia la gnosis». Cuadernos Hispanoamericanos, 391-393, 46-69. RoBerTs, G. (1983): «Presencia de lo demoníaco en Abaddón el exterminador, de Ernesto Sabato». Ibid, 526-535. Lojo DE BEUTER, M. L. (1983): «Simbolismo del ritual erótico en Abaddón el exterminador». Ibid, 551-569. Más tarde Bacarisse ha publicado en castellano los resultados de su trabajo sobre este tema: «La cosmología gnóstica de Sabato: una interpretación de Abaddón el exterminador", en VÁzoUEz BIGI, M. (Ed.) (1985): Epica dadora de eternidad. Sabato en la crítica americana y europea. Buenos Aires, 193-219.

(7) (1985). «Sobre torres y cloacas. La heterodoxia de Ernesto Sabato». Quirón, 16, núm. 2-4, 57-68. (1987). "Vers le volcan de chair. Le voyage onirique d'Ernesto Sabato vers la connaissance». Frénésie. Histoire, Psychiatrie, Psychanalise, 3, 129-148. (1987). «Ernesto Sabato. Ojos para lo sagrado». Revista Iberoamericana, LIII, núm. 141, 933-943. (1988). «El ojo sexual. Sexo y conocimiento en la obra de Ernesto Sabato». Jano, 825, 84-89.

(8) La exposición más sintética es la que figura en las páginas 58 a 62 de mi trabajo de 1985.

(9) Además de los estudios citados en la nota 7 el tema ha sido estudiado por mí en Con los ojos de Perséfone. Una lectura de Ernesto Sabato (Madrid, 1989), donde intento probar que el dualismo maniqueo cumple, en la obra de Sabato, un papel fundamentalmente simbólico respecto de otras influencias filosóficas que apuntan a este mismo problema de la escisión percibida y la búsqueda de la unidad frente al caos. 
(10) Jung, C. G. (1989): Psicología y alquimia. Barcelona, Plaza y Janés, p. 41.

(11) Ibid., p. 15.

(12) Ibid., p. 35

(13) Ibid., pp. 225-226.

(14) Bacherlard, G. (1974): La terre et les rêveries du repos. París, José Corti, p. 41.

(15) JUNG, C. G. (1989): p. 51.

(16) Sabato, E. (1978b): Sobre héroes y tumbas. Barcelona, p. 305.

(17) SABATO, E. (1978b): p. 306-307.

(18) Eliade, M. (1962): Mephistopheles et l'androgyne. París. Hay traducción española: (1984). Mefistófeles y el andrógino. Barcelona.

(19) Sabato, E. (1978a): El túnel. Barcelona, pp. 130-131.

(20) SABATO, E. (1987b): p. 204.

(21) Sabato, E. (1978b): pp. 340 y 431.

(22) JUNG, C. G. (1989): p. 56.

(23) Sabato, E. (1978c): Abaddón el exterminador. Barcelona, p. 166.

(24) Sabato, E. (1978b): p. 425.

(25) JUNG, C. G. (1961): La psicología de la transferencia. Buenos Aires, p. 83.

(26) SABATO, E. (1978b): p. 83.

(27) SABATO, E. (1978b): p. 445-446.

(28) SABaTo, E. (1978c): p. 420.

(29) JUNG, C. G. (1961): p. 82.

(30) Sabato, E. (1978c): pp. 447-448.

(31) JUNG, C. G. (1961): p. 131.

(32) Sabato, E. (1970): Uno y el universo. En: Ensayos, Buenos Aires, p. 15.

(33) JUNG, C. G. (1989): p. 19.

(34) JUNG, C. G. (1989): p. 49.

(35) Nietzsche, F. (1980): Also sprach Zarathustra. En: Werke, Ed. K. Schlechta, München, vol. III, p. 332.

(36) Sabato, E. (1978c): pp. 473-474. 


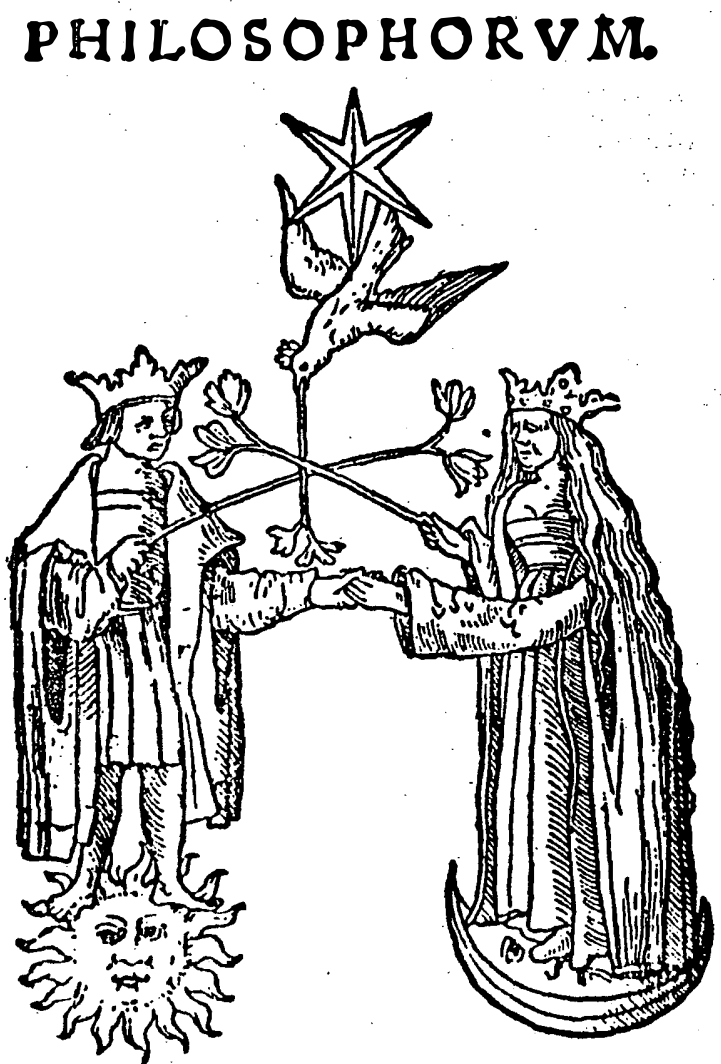

Nota benc: In arte no/trimagifterijnihil eft secretum celatũ a Plulofophis excepto fecreto artis, quod arts son licet cuiquam reuelare, quod fi fieret ille ma ledicerecur, \& indignationem domini incurs reret, \&lapoplexia morcretur. \#ULuare oms inis error in arte exiftit, cx cos cuod debitam

Fig. 2

i4 


\section{CONIVNCTIO SIVE Cottus.}

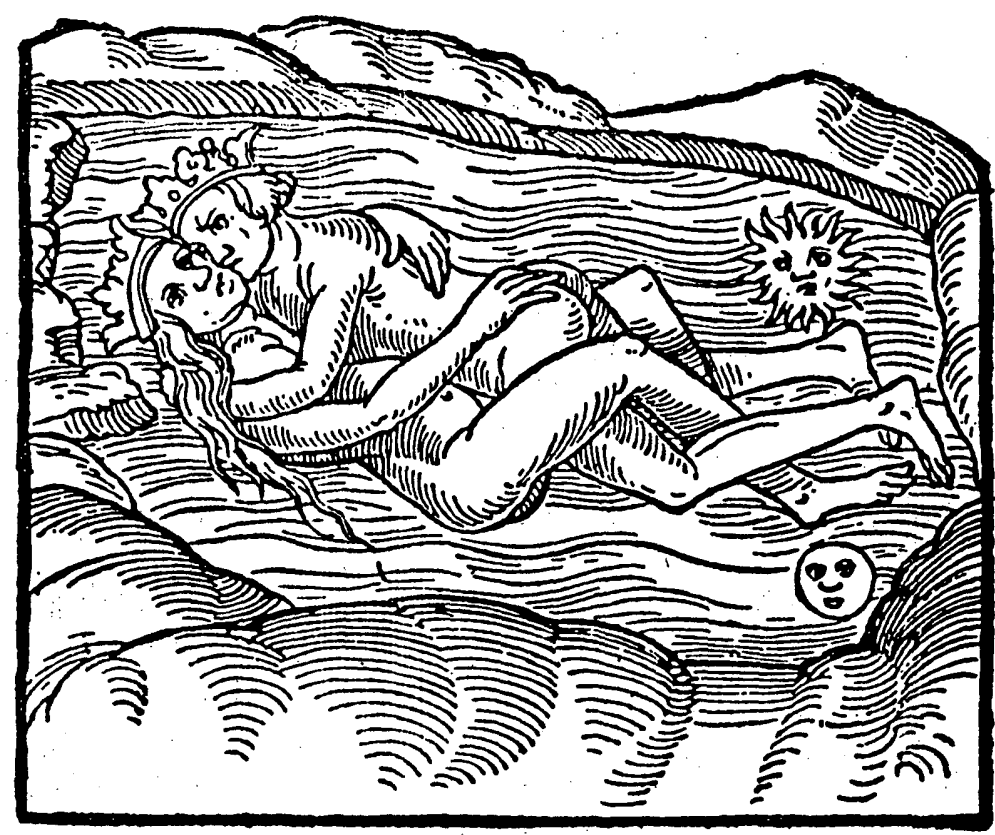

(1) Runa dard meyn vmbgeben/vno fuffe myitme/ Dirftu fdoon/ftarcl/vno gewoltig als id byn. O Eol/Oubift vber alle lied)eguertenuten/

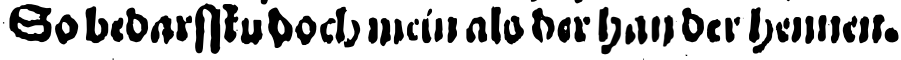

\section{ARISLEVS IN'VISIONE.} Coniunge ergo filium tuum Gabricum. diles Etiorem tibi in omnibusfilijs tuiscum fua forore Beya

Fig. $s$ 


\section{PHILOSOPHORVM. \\ CONCEPTIOSEV PVTRE}

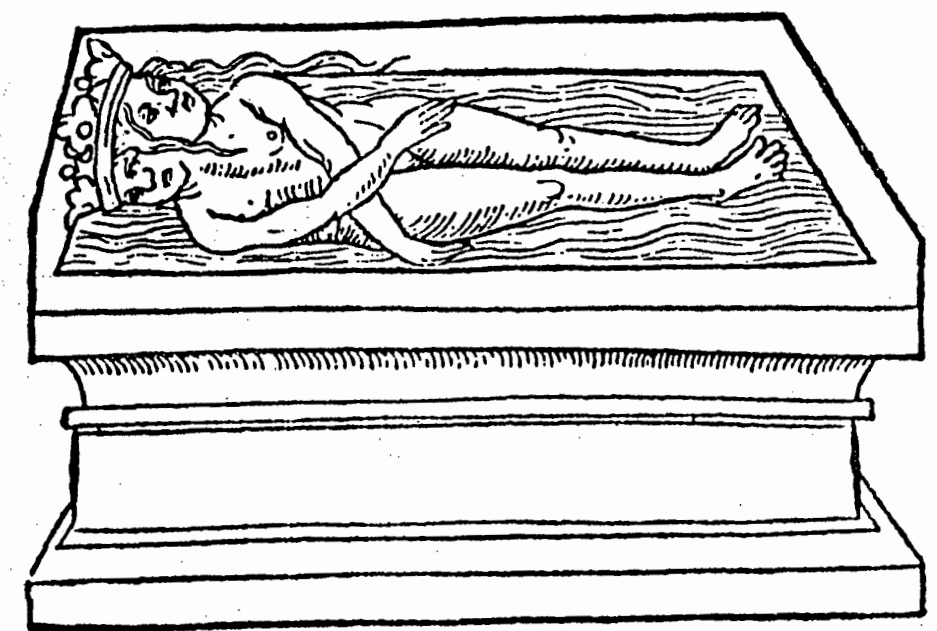

Boyeligcntónig vno Eóningin oot/

Die fale fdeyor fi:t) nut groffir not.

\section{ARIST.OTELES REX ET Phloopoplus.}

\section{Vnquam vidi aliquod animatum crefcere N fine putrefastione, nifi autem fiat putris auminuanum crit opus alchimicum.}

Fig. 7

[123] 


\section{ROSARIVMI \\ ANIME EXTRACTIO VEL \\ ingeragnatio.}
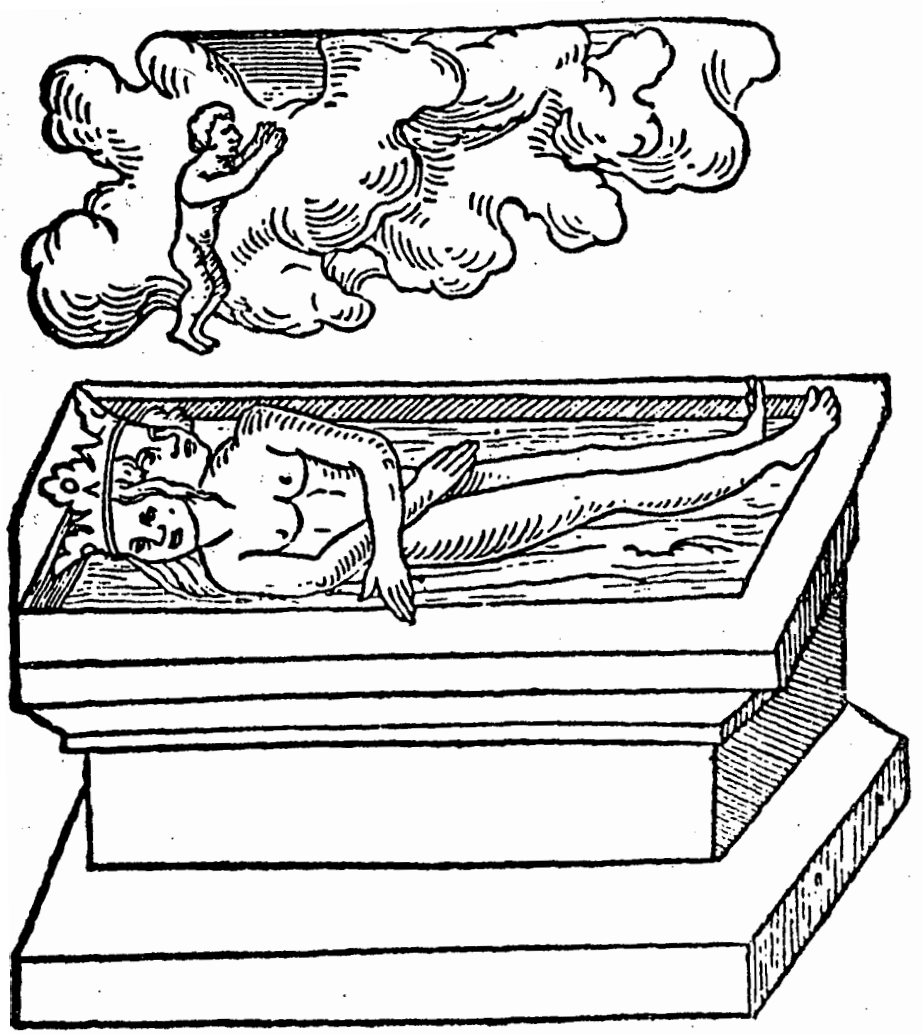

\section{Bjye texlan fid oie vier element/ \\ aus Demi loyb fabesot fid) Die fale belbendet.}

De.

Fip. 8

[134] 


\section{PHILOSOPHOR VM.}

\section{ANIMAIVBILATIO SEV Ortus feu Sublintatio.}
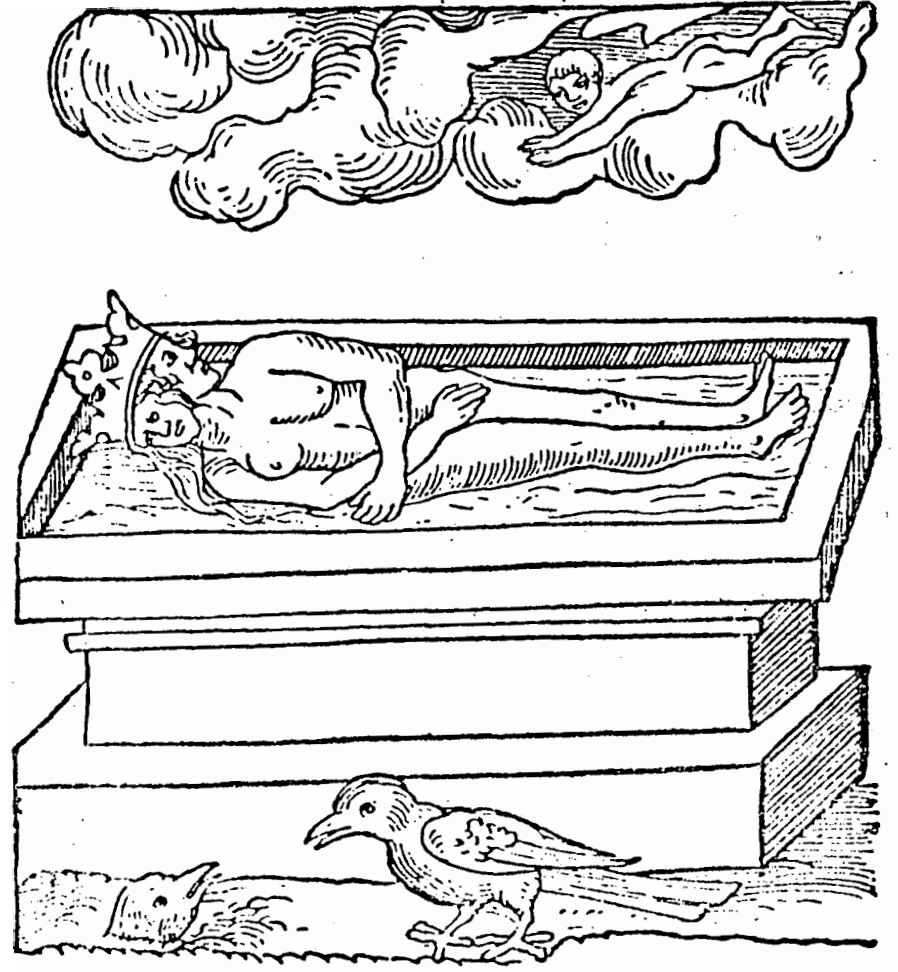

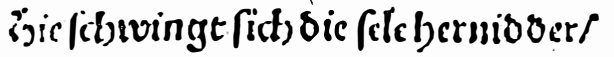

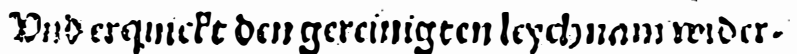

Le iij

lig. 10

[150] 


\section{ROSARIVM. PERFECTIONIS ostenglo.}

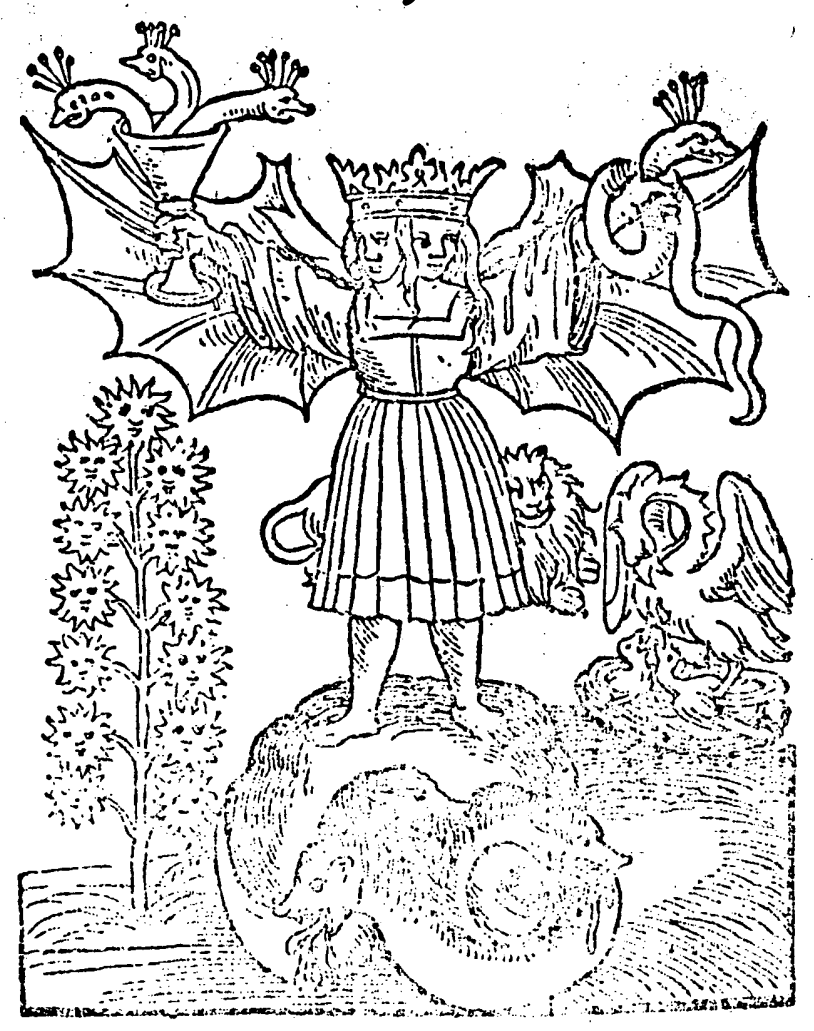

ADIGNARNGIS.

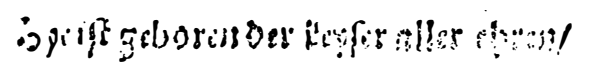

Rosurium Pribloseplorom, lisu. asisia

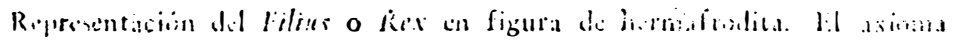

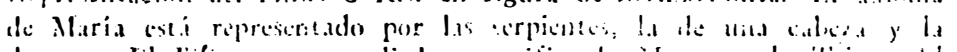

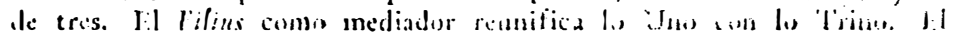

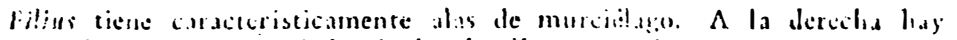

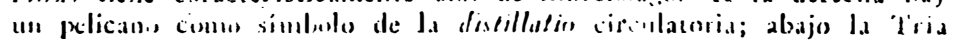

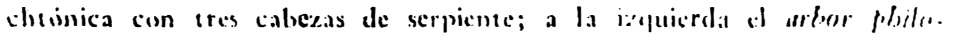
sophicia on lis liojas ale cirie. 